\title{
A prospective study of antimicrobial utilization in post-operative care unit of a teaching hospital in South India
}

\author{
Mohammed Naseeruddin Nadeem ${ }^{1 *}$, Maliha Maqdoom²
}

\author{
${ }^{1}$ Department of Pharmacology, Deccan College of Medical Sciences, Hyderabad, Telangana, India \\ ${ }^{2}$ Department of Physiology, Ayaan Institute of Medical Sciences, Hyderabad, Telangana, India
}

Received: 22 November 2019

Accepted: 07 January 2020

\author{
*Correspondence: \\ Dr. Mohammed Naseeruddin Nadeem, \\ Email:nad040@gmail.com
}

Copyright: (C) the author(s), publisher and licensee Medip Academy. This is an open-access article distributed under the terms of the Creative Commons Attribution Non-Commercial License, which permits unrestricted non-commercial use, distribution, and reproduction in any medium, provided the original work is properly cited.

\begin{abstract}
Background: Surgical site infections, a common cause of morbidity and mortality in hospitalized patients can be prevented using an antimicrobial agent (AMA) as prophylaxis. Inappropriate use of AMA leads to antimicrobial resistance.

Methods: A prospective study was conducted on 208 patients in Owaisi Hospital and Research Centre (OHRC) for a period of 6 months on post-surgical patients admitted in the postoperative care unit. Included in the study were postoperative patients aged 18 years and above, who were willing to participate in the study. Data related to demography of the patients and the AMAs used in these patients was collected and analysed.

Results: Majority of the patients belonged to the age group 50 to 59 years (32\%) followed by 40 to 49 age group (23\%). Male patients (54\%) were more than females. Common route of administration was intravenous $(89 \%)$ and the most common dosing frequency was thrice a day (54\%). Most AMAs were used in combinations. Metronidazole $(62 \%)$ was the most commonly prescribed AMA, followed by ceftriaxone $(55 \%)$.

Conclusions: Cephalosporins were the preferred antimicrobials for surgical prophylaxis of aerobic infections prescribed in $74 \%$ of cases, while metronidazole was used as the primary antimicrobial agent to prevent anaerobic infections. AMA utilization needs to be continuously evaluated in post-operative units of the surgery departments in order to promote rational prescribing to decrease morbidity, cost of therapy and to contain the problem of developing AMA resistance in the region.
\end{abstract}

Keywords: Antimicrobial agents, Surgical site infection, Prophylaxis, Drug utilization

\section{INTRODUCTION}

Surgical site infections (SSIs) are the most common infections in patients who have underwent surgery, which had led to an increase in hospital stay, healthcare costs, complications, morbidity and mortality. Accounting for about $17 \%$ of the hospital acquired infections, SSIs resulted in an increased usage of antibiotics which lowered the morbidity and mortality related to SSIs. However, this increased antibiotic utilization had been a major driving force for development of antibiotic resistance. ${ }^{1}$
According to the centre for disease control and prevention (CDC), there are three types of SSIs which includes superficial incisional SSIs (involving only skin and subcutaneous tissue), deep incisional SSIs (involving underlying soft tissue) and organ or space SSIs. Prophylactic use of antimicrobial agents (AMAs) before, during and after surgery reduces and minimizes the incidence of post-operative surgical site infections and complications. ${ }^{2}$ CDC fosters a rational choice and an appropriate use of AMAs, at the same time shunning the irrational practice of excessive use of AMAs for a longer duration than required. 
Between 2000 and 2010, consumption of antibiotic drugs had increased by $36 \%$. Brazil, Russia, India, China, and South Africa accounted for $76 \%$ of this increase, with India's usage alone of antibiotics increased by $62 \%$ from 2001 to 2010 . Indians consumed 12.9 billion antibiotic pills in 2010, up from 8 billion in $2001 .^{3}$ Globally, the two last-resort classes of antibiotic drugs like carbapenems and polymixins have also showed an increased utilization by $45 \%$ and $13 \%$ respectively, during this period. Cephalosporins, broad-spectrum penicillins and fluoroquinolones accounted for $55 \%$ increased utilization during this 10 year period. ${ }^{3}$ According to a survey done by Johns Hopkins School of Medicine, India was found to be the leading consumer of antibiotics, with an increased utilization (103\%) from 3.2 defined daily doses (DDDs) in 2000 to 6.5 billion DDDs in 2015 and an increased consumption of 8.2 in 2000 DDS per 1000 inhabitants per day to 13.6 DDSs' per 1,000 inhabitants per day in 2015 (63\% increase). ${ }^{4}$

WHO initiated a "global action plan on antimicrobial resistance", with 5 planned objectives. ${ }^{5}$ The objectives were improving awareness and understanding of antimicrobial resistance; strengthening surveillance and research; reducing the incidence of infection; optimizing the use of antimicrobial medicines; ensuring justifiable investment in countering antimicrobial resistance.

Irrational prescriptions are of common occurrence in clinical practice, important reasons of which being lack of knowledge about the rationality of the drug to be used, and also the unethical drug promotion. ${ }^{6}$

This non-judicious, indiscriminate and inappropriate use of AMAs has led to an increased risk of bacterial drug resistance, thereby increasing hospital expenses. ${ }^{7,8}$

Antimicrobial resistance patterns can vary regionally and even among different hospitals within the same community.

Drug utilisation Study (DUS) was defined by WHO as "the studies of marketing, distribution, prescription and use of drugs in a society, with special emphasis on the resulting medical, social and economic consequences". 9 DUS are pre requisite for the formulation of drug policies and offer useful methods for teaching and training in drug therapy. DUS identifies the problems that arise from drug usage in healthcare delivery system and highlights the current approaches to the rational use of drugs. ${ }^{10}$ AMA Utilization study is synonymous to DUS, in which auditing of AMAs can be done, that enables monitoring and evaluation of AMA prescribing patterns and suggest necessary modifications in prescribing practices to achieve rational therapeutic practice.

The objectives of the present study are to evaluate and compare the utilisation patterns of AMAs in the post operative ward and to generate data on the extent of rationality in prescribing these AMAs.

\section{METHODS}

A prospective, observational study was done in Owaisi hospital and research centre (OHRC) for a period of 6 months from November 2018 to April 2019 on postsurgical patients admitted in the postoperative care unit. Approval of the institutional ethics committee was taken before the start of study. A total of 208 patients who met the inclusion criteria, were included in the study, and their data was recorded. Patient profile forms were filled which consisted of details of demography, history, diagnosis and antimicrobial therapy administered to the patients. Information like the generic name of AMA and its combination with other AMAs, their frequency and dosages were collected. National treatment guidelines for antimicrobial use in infectious diseases of 2016 were taken into consideration for evaluation of the data of antibiotic utilization.

\section{Inclusion criteria}

Inclusion criteria were patients of age above 18 years of either gender, who has undergone surgery and patients willing to participate in the study.

\section{Exclusion criteria}

Patients undergoing minor surgical procedures (where prophylactic AMAs not required), patients with known hypersensitivity to antibiotics, patients with pre-existing infections; patients with liver disease and renal impairment; diabetes mellitus patients; immunecompromised patients were excluded.

\section{Source of data}

The data for the study was collected by using medical records like patient case sheets of the in-patients; laboratory investigational data reports.

\section{Method of data collection}

Patients were enrolled into the study, after taking their consent by considering inclusion and exclusion criteria. The patient's medical records were reviewed from surgery unit cases and the collected data was entered in the case record forms. The data to be entered comprised of the patient's demographic details like age, sex and disease information including diagnosis. The details of the AMAs prescribed and any other therapy given to the patients were collected in terms of dose, duration, frequency and route of administration. Patients were followed up to the time of discharge and their length of stay in the hospital stay was recorded. Data was collected as per proforma, prepared in advance using WHO criteria, taking into consideration the patient's demographic characteristics, disease condition, AMAs prescribed from the date of admission till discharge as well as the operative notes entered. The surgery status 
was assessed for any infection. In case of any surgical site infection, the treatment given for that was also collected.

Data was analyzed according to the WHO/INRUD indicators for number of drugs per prescription, number of antibiotics per prescription, number of drugs prescribed by generic name, number of medicines prescribed from WHO list of essential medicines (EML) and number of injections to be administered per prescription.

Descriptive statistical analysis was done using Microsoft excel software and the results were presented as percentages and means.

\section{RESULTS}

A total of 208 patients were included in this study. Agewise distribution showed that the most number of the patients were seen in the ages ranging from 50 to 59 years, which included 67 patients (32\%), followed by those in the 40 to 49 age group with 48 patients $(23 \%)$. Male patients (54\%) were more than females.

Regarding the frequency of drug administration per day, it was found that twice daily regimen was being followed more commonly, as seen in 111 patients (54\%).

Most common route of administration was intravenous route $(89 \%) .92 \%$ of prescriptions used trade names of AMAs, while only $8 \%$ prescriptions used generic names for prescribing AMAs. Most of the AMAs were used in combinations. Cephalosporins were the most preferred group of antibiotics which were prescribed for $74 \%$ of patients. The cephalosporins used were ceftriaxone $(55 \%)$, cefotaxime $(14 \%)$ and cefoperazone $(5 \%)$. Metronidazole (62\%) was the most commonly prescribed AMA, followed by ceftriaxone $(55 \%)$.

Table 1: Age distribution of patients.

\begin{tabular}{|lll|}
\hline $\begin{array}{l}\text { Age } \\
\text { (in years) }\end{array}$ & Patients & Percentage (\%) \\
\hline$<\mathbf{2 0}$ & 6 & 3 \\
\hline $\mathbf{2 0 - 2 9}$ & 25 & 12 \\
\hline $\mathbf{3 0 - 3 9}$ & 35 & 17 \\
\hline $\mathbf{4 0 - 4 9}$ & 48 & 23 \\
\hline $\mathbf{5 0 - 5 9}$ & 67 & 32 \\
\hline $\mathbf{6 0 - 6 9}$ & 27 & 13 \\
\hline
\end{tabular}

Table 2: Gender distribution of patients.

\begin{tabular}{|lll|}
\hline Gender & Patients & Percentage (\%) \\
\hline Male & 112 & 54 \\
\hline Female & 96 & 46 \\
\hline
\end{tabular}

Table 3: Frequency of antimicrobial used per day.

\begin{tabular}{|lll|}
\hline & Frequency & Percentage $(\%)$ \\
\hline Once daily & 38 & 18 \\
\hline Twice daily & 111 & 54 \\
\hline Thrice daily & 59 & 28 \\
\hline
\end{tabular}

Table 4: Route through which antimicrobial administered.

\begin{tabular}{|lll|}
\hline Route & Frequency & Percentage $(\%)$ \\
\hline IV & 185 & 89 \\
\hline Oral & 23 & 11 \\
\hline
\end{tabular}

Table 5: Antimicrobial prescribed by generic or trade name.

\begin{tabular}{|lll|}
\hline & Frequency & Percentage $(\%)$ \\
\hline Generic name & 191 & 92 \\
\hline Trade name & 17 & 8 \\
\hline
\end{tabular}

Table 6: Prescribing pattern of antimicrobial agents.

\begin{tabular}{|lll|}
\hline $\begin{array}{l}\text { AMAs used } \\
\begin{array}{l}\text { Ceftriaxone and } \\
\text { metronidazole }\end{array}\end{array}$ & 59 & 28 \\
\hline $\begin{array}{l}\text { Cefotaxine and } \\
\text { metronidazole }\end{array}$ & 23 & 11 \\
\hline $\begin{array}{l}\text { Ceftriaxone and amikacin } \\
\text { Ceftriaxone }\end{array}$ & 18 & 9 \\
\hline $\begin{array}{l}\text { Ciprofloxacin and } \\
\text { metronidazole }\end{array}$ & 16 & 8 \\
\hline $\begin{array}{l}\text { Ceftriaxone and sulbactum } \\
\text { Amoxycillin and clavulanic } \\
\text { acid }\end{array}$ & 13 & 8 \\
\hline $\begin{array}{l}\text { Amoxycillin, gentamycin and } \\
\text { metronidazole }\end{array}$ & 11 & 6 \\
\hline $\begin{array}{l}\text { Cefoperazone and sulbactam } \\
\text { Ceftriaxone and gentamycin }\end{array}$ & 10 & 6 \\
\hline $\begin{array}{l}\text { Levofloxacin and } \\
\text { metronidazole }\end{array}$ & 8 & 5 \\
\hline $\begin{array}{l}\text { Cefotaxime, metronidazole } \\
\text { and amikacin }\end{array}$ & 6 & 5 \\
\hline $\begin{array}{l}\text { Piperacillin, tazobactam and } \\
\text { metronidazole }\end{array}$ & 6 & 4 \\
\hline \begin{tabular}{l} 
Amoxycillin and gentamycin \\
\hline
\end{tabular} & 2 & 4 \\
\hline
\end{tabular}

\section{DISCUSSION}

In this study, all patients who underwent surgery were administered AMAs as prophylaxis. Most of the patients $(89 \%)$ received the AMAs via parenteral route, with intravenous route being the one preferred. A similar study done by Khade et al showed that the most preferred route of drug administration was intravenous route in $68 \%$ cases. $^{11}$

In the present study, it was observed that most of the AMAs were used as combinations. Monotherapy of 
AMAs was seen in only 16 prescriptions $(8 \%)$ with the third-generation cephalosporin, ceftriaxone. Also, the most commonly prescribed AMA was metronidazole, which was repeated in 129 prescriptions $(62 \%)$, followed by ceftriaxone in 114 patients $(55 \%)$. This finding is contrary to other studies by Sharma et al and Alemkere which showed that ceftriaxone was the most commonly prescribed AMA at $78 \%$ and $84 \%$ respectively. ${ }^{12,13}$

Aminoglycoside AMAs, like Amikacin and gentamicin, which covers only gram negative organisms, were prescribed in $24(12 \%)$ patients and $21(10 \%)$ patients respectively. Fluoroquinolones like Ciprofloxacin and levofloxacin were used in $16(8 \%)$ and $8(4 \%)$ patients respectively. Even though fluoroquinolones are proved to be highly effective agents for use in post-operative prophylaxis, they were found to be used less frequently in this study. An increased use of fluoroquinolones will prove beneficial, as it could replace the use of cephalosporins to some extent, thereby alleviating the likelihood of resistance development among cephalosporins.

In this study it was found that a wide range of AMAs were used, covering a broad range of microbial spectrum. Among the combination of AMAs, the most common was ceftriaxone with metronidazole in 59 patients (28\%). Kulkarni et al showed that Ceftriaxone along with metronidazole was the most preferred AMA combination (84\%) in a similar study. ${ }^{14}$ Another study done by Naik et al in India showed similar results as that of our study that metronidazole was the most commonly used AMA. ${ }^{15}$ However, in contrast to findings of the present study, a study conducted by Venkateshwar in India, showed cephalosporins to be most frequently used. ${ }^{16}$ Khan et al showed that third generation cephalosporin like ceftriaxone was the most prescribed AMA used in 92\% cases. $^{17}$

The second most common AMA combination in this study was cefotaxime and metronidazole in 23 patients (11\%). Ceftriaxone was also combined with amikacin in 18 patients (9\%). Piperacillin and tazobactem combination were used in 6 prescriptions in this study, which is not recommended for prophylaxis, unless indicated.

$92 \%$ of the prescriptions used brand names in this study, which is a similar to a finding by Khade et al in a similar study done in south India, in which $80 \%$ of drugs were used as trade names. ${ }^{11}$

Culture sensitivity testing was not done in any of the cases, and it was observed that most of the prescriptions followed an empirical approach. Polypharmacy was observed in some cases, where AMAs were prescribed along with other drugs like Non-steroidal antiinflammatory drugs, multivitamins and proton pump inhibitors. Polypharmacy must be avoided for prophylaxis, unless indicated. Most of the AMAs (97\%) prescribed were from EML, except for six prescriptions in which AMAs used were not from the EML. 41 (20\%) of prescriptions was found to have AMAs in the form of fixed drug combinations. The average number of antibiotics prescribed per patient was calculated to be 2.14 .

An excessive prescribing of AMAs in combinations is irrational, especially for prophylactic use. In order to curb the excess and inappropriate use of AMAs, a hospital formulary enlisting the recommended AMAs is required to be prepared and strictly implemented. Measures are needed to be taken by the hospital for procuring and adequately supplying AMAs enlisted in EML and the prescriber must ensure that the AMAs being prescribed are enlisted in EML provided. There is a need to create awareness among prescribers regarding the current difficult situation of increasing AMA resistance. For this, continuing medical education, workshops and awareness campaigns should be conducted at regular intervals. AMA culture sensitivity testing must be encouraged, to improve therapeutic outcomes, especially in non-responding and complicated SSIs.

Detailed knowledge of rational drug use, antibiotic sensitivity testing and clinical judgment in treating infections is required for the optimal and judicious selection of AMAs. To streamline AMA use in India, antibiotic guidelines need to be implemented in every hospital, which requires more antimicrobial utilization studies to be carried out in our existing setups. There is an urgent need for regular and frequent evaluations of AMA prescription patterns and AMA utilization studies.

\section{CONCLUSION}

For surgical prophylaxis of aerobic infections, cephalosporins were the most preferred antimicrobials used in $74 \%$ patients. Cephalosporins were used either alone or in combination with other antimicrobials. Among the cephalosporins, ceftriaxone was the most commonly used, followed by cefotaxime. For surgical prophylaxis of anaerobic infections, metronidazole was the most preferred antimicrobial used in $62 \%$ patients. Multiple antimicrobials were more frequently used as combinations, which showed an empirical approach while prescribing AMAs. Also, culture sensitivity testing was not done for any of the cases. This inappropriate antimicrobial use had resulted in an increased antimicrobial resistance and higher cost of therapy. Effective use of a hospital formulary, essential medical list and strategies to increase awareness among healthcare professionals about AMA resistance, through continuing medical education and awareness campaigns are the need of the hour. A limitation of the present study is the relatively small number of patients covered, the findings of which do not represent the antimicrobial utilization pattern of the entire population in south India. Further similar studies are required to be done at multiple hospitals and at frequent intervals in south India to give a 
better and generalized understanding of the current trends in antimicrobial use and in the process, to curb the development of its resistance in the long term.

\section{ACKNOWLEDGEMENTS}

Authors would like to thank all the faculty and postgraduates of pharmacology and surgery departments.

\section{Funding: No funding sources}

Conflict of interest: None declared

Ethical approval: The study was approved by the Institutional Ethics Committee

\section{REFERENCES}

1. Perencevich EN, Sands KE, Cosgrove SE, Guadagnoli E, Meara E, Platt R. Health and Economic Impact of Surgical Site Infections Diagnosed after Hospital Discharge. Emerg Infect Dis. 2003;9(2):196-203.

2. Bratzler DW, Houck PM. Antimicrobial prophylaxis for surgery: an advisory statement from the National Surgical Infection Prevention Project. Clin Infect Dis. 2004; 38:1706-15.

3. Van Boeckel TP, Gandra S, Ashok A, Caudron Q, Grenfell BT, Levin SA, Laxminarayan R. Global antibiotic consumption 2000 to 2010: an analysis of national pharmaceutical sales data. Lancet Infect Dis. 2014;14(8):742-50.

4. Klein EY, Van Boeckel TP, Martinez EM, Pant S, Gandra S, Levin S, Goossens H and Laxminarayan R. Global increase and geographic convergence in antibiotic consumption between 2000 and 2015 . PNAS. 2018;115(15):E3463-E3470.

5. World health organization. Antibiotic resistance. World health organization India; 2018. Available at: https://www.who.int/news-room/factsheets/detail/antibiotic-resistance. Accessed on 3 January 2020.

6. Carlet J. Epidemiology and control of antibiotic resistance in the intensive care unit. Curr Opin Inf Dis. 2004; 17:309-16.

7. Georgeet SS, Varghese SR, Samuel CJ. Evaluation of antibiotic prescribing patterns among medical practitioners in North India. Ind J Bas App Med Res. 2013;8(2):952-7.
8. Thomas B, Matthew L, Jose J, Rathinavelu M, Shanmugam S, Kumar K. Assessment of antibiotic sensitivity pattern of microorganisms and their costeffectiveness at a private corporate hospital in south India. Asian J Pharm Clin Res. 2014;7:155-9.

9. Laporte JR, Porta M, Capella D. Drug utilization studies: a tool for determining the effectiveness of drug use. Br J Clin Pharmacol. 1983;16(3):301-4.

10. Bergman U, Popa C, Tomson Y, Wettermark B, Einarson TR, Aberg H, et al. Drug utilization 90\%- a simple method for assessing the quality of drug prescribing. Eur J Clin Pharmacol. 1998;54(2):113-8.

11. Khade A, Bashir MSM, Sheethal A. Prescription pattern in the department of surgery in a tribal district hospital of Andhra Pradesh, India. Ann Med Health Sci Res. 2013;3(3);438-41.

12. Sharma P, Goel D. Utilization assessment of antimicrobial prophylaxis in surgical patients at tertiary care teaching hospital. Saudi J Health Sci. 2018;7:23-7.

13. Alemkere G. Antibiotic usage in surgical prophylaxis: A prospective observational study in the surgical ward of Nekemte referral hospital. PLoS ONE. 2018;13(9):e0203523.

14. Kulkarni RA, Kochhar PH, Dargude VA, Rajadhyakshya SS, Thatte UM. Patterns of antimicrobial use by surgeons in India. Indian J Surg. 2005;67:308-15.

15. Vadajiya S, Naik V, Mevada A. A study of antimicrobial drug utilisation pattern and appropriateness in the surgical units of the civil hospital, Ahmedabad. Int J Pure Appl Biosci. 2014;2:77-82.

16. Venkateshwar. Drug utilization study of antibiotics in surgical ward of a tertiary care hospital. Int J Chem Pharm Sci. 2015;6(1).

17. Khan AK, Mirshad PV, Rashed MR, Banu G. A study on the usage pattern of antimicrobial agents for the prevention of surgical site infections in a tertiary care teaching hospital. J Clin Diagn Res. 2013;7(4):671-4.

Cite this article as: Nadeem MN, Maqdoom M. A prospective study of antimicrobial utilization in postoperative care unit of a teaching hospital in South India. Int J Basic Clin Pharmacol 2020;9:310-4. 